\title{
SCIENTIFIC REPORTS

\section{Cold plasma treatment to release dormancy and improve growth in grape buds: a promising alternative to natural chilling and rest breaking chemicals}

\begin{abstract}
Z. Mujahid ${ }^{1}$, T. Tounekti $\mathbb{D}^{2} \&$ H. Khemira $\mathbb{D}^{2 *}$
Winter dormancy of temperate zone perennial plant species is commonly released by chilling temperature. If the duration of the cold weather is not adequate, plant growth becomes disorganized leading to reduced growth, spread out flowering and fruit maturation and often reduced yield. In mildwinter regions, growers commonly resort to spraying their trees with chemicals such as hydrogen cyanamide to compensate for the lack of chilling to ensure good growth and yield. Although effective, most of these chemicals are highly toxic; unfortunately, there is no effective and environmentally friendly alternative which can be used to release dormancy. In this work, we present a cold plasma treatment-based method which can effectively release the dormancy of grape buds. We have found that exposing grape buds to plasma provides improvement of several growth parameters including higher, faster and more synchronous budbreak and more vigorous vegetative growth, comparatively similar to or better than natural chilling. Biochemical analyses of bud tissue suggest that the plasma treatment triggered a marked transient oxidative stress as indicated by the increase in the concentrations of free proline, malondialdehyde (MDA) and hydrogen peroxide $\left(\mathrm{H}_{2} \mathrm{O}_{2}\right)$. Proline appears to have played a key role; as a compatible osmolyte, it may have protected cellular structures against free radicals and as a signaling molecule, it may have induced the events leading to dormancy release. We anticipate that our work will provide a starting point for the development of novel plasma-based tools and methods to treat dormant plants. The plasma treatment method may allow higher agricultural production in several regions of the world at risk of becoming marginal for the cultivation of certain crops due to global warming.
\end{abstract}

Several fruit vines such as grape and kiwi, fruit and nut trees and ornamental woody species cease active growth in early fall, lose their leaves then become dormant in the winter. Such plants are considered as endodormant, i.e., their growth is inhibited from within the dormant structures themselves (the buds) ${ }^{1}$. Under natural conditions, endodormancy is released by the cold of winter. Once the chilling requirement of the plant's structure (bud or seed) is met, it resumes active growth if environmental conditions are suitable ${ }^{2,3}$. If the chilling requirement of a plant is not met such as in mild-winter regions, budbreak becomes erratic and asynchronous leading to reduced vegetative growth, spread out flowering and fruit maturation and often reduced yield ${ }^{4-6}$. Increasingly, temperate zone fruit trees and vines are cultivated in warmer regions beyond their natural habitat as well as temperatures are rising due to global warming and climatic change, which makes dormancy critical for future agriculture ${ }^{7}$.

Currently, growers resort to the application of artificial rest-breaking agents such as thiourea, calcium cyanamide, potassium nitrate and hydrogen cyanamide to promote budbreak and manipulate flowering of the trees $^{2}$. For instance, hydrogen cyanamide-based chemicals have been used effectively on several fruit crops such grapevines ${ }^{8-10}$ and kiwi vines ${ }^{11}$. However, the effectiveness of the treatment depends on the time of application ${ }^{9}$; besides, the use of this chemical has been restricted in several countries because of its high toxicity to humans 
and wildlife. Furthermore, most of these chemicals are phytotoxic to the plant itself and neighbouring crops. Therefore, there is an urgent need to find safer but equally effective alternatives to hydrogen cyanamide.

Rest-breaking chemicals such as hydrogen cyanamide were shown to cause sub-lethal stress within the treated tissue which leads to endodormancy release ${ }^{12}$; the mechanisms involved are still not well understood. The available evidence indicates that dormancy interruption is tightly associated with oxidative processes taking place in the dormant structure ${ }^{13-15}$. In dormant grapevine buds, hydrogen cyanamide inhibits both the activity of the antioxidant enzyme catalase (CAT, EC 1.11.1.6) and the expression of its gene ${ }^{13}$ leading to a transient accumulation of hydrogen peroxide $\left(\mathrm{H}_{2} \mathrm{O}_{2}\right)$ which regulates the release of endodormancy and budbreak ${ }^{15,16}$. Most genes expressed during dormancy release are related to the oxidative processes and stress responses within the cell ${ }^{17}$. It was therefore suggested that grape dormancy and its release are controlled by the changes in $\mathrm{H}_{2} \mathrm{O}_{2}$ metabolism. However, how hydrogen cyanamide exactly affects the reactive oxygen species (ROS) regulatory network during grapevine dormancy release remains unclear. The hydrogen cyanamide treatment also stimulates the accumulation of the amino acid proline and the polyamine putrescine which act as free radical scavengers, molecular messengers and also as sources of nitrogen and carbon for the rapid tissue growth which follows budbreak ${ }^{15,18}$.

Cold atmospheric plasma has recently emerged as a promising simple, low-cost and efficient tool for the disinfection of water and food and even human $\operatorname{skin}^{19-21}$. In addition to the sterilisation of articles and surfaces, it is investigated worldwide for the treatment of plant seeds ${ }^{22-26}$. Plasma can generate electron, ions, radicals, reactive species and light radiation including $\mathrm{UV}^{27}$. Part or a combination of these components have been utilised for the treatment of the seeds to induce biological responses such as germination ${ }^{26,28,29}$, seedling growth ${ }^{22,24,30}$, stress tolerance $^{31}$ and improvement in yield ${ }^{32}$. They have been tested on seeds of several species such as tomato ${ }^{33}$, wheat ${ }^{28}$, sunflower ${ }^{22}$ and quinoa ${ }^{23}$. It was observed that the plasma etches the external surface of the seed teguments ${ }^{34}$; this possibly facilitates imbibition and advances germination.

In the present work, we report a novel effect of plasma treatment of dormant grape shoots which results in the release of bud dormancy. This study examined the effect of plasma treatment on growth and antioxidants' status in dormant buds of Vitis vinefera L. cv. Muscat of Alexandria. We evaluated the changes in CAT activity and the concentrations of $\mathrm{H}_{2} \mathrm{O}_{2}$, Malondialdehyde (MDA) which is considered a marker of damage due to oxidative stress and proline. Our results show that plasma-based treatment can advance and synchronize budbreak and increase shoot vigour. The literature research suggests that this is the first report on the use of plasma to break bud dormancy in any plant species.

\section{Materials and Methods}

Plant material. Initial experiments were carried out in small replicates on shoots of the local grape cultivar El-Reizki, for widespread conditions of gas, treatment time, power and plasma type. Some of the plasma treatments stood out to be very effective in releasing bud dormancy.

More detailed experiments were performed on lignified canes of the common grape cultivar Muscat of Alexandria with a diameter of 0.4 to $1 \mathrm{~cm}$ which were collected in late November from several vines in a vineyard in Abha mountains region of Saudi Arabia. The canes were cut into short single-node segments to preclude the influence of apical dominance and to allow the material to fit into the plasma chamber.

In total, five distinct sample were studied. Three sets of cuttings were treated with plasma for 2,5 or $10 \mathrm{~min}$ utes. The fourth set of cuttings were wrapped in a plastic bag and kept in a refrigerator at $4{ }^{\circ} \mathrm{C}$ for one month so to receive enough chilling to release their dormancy (the equivalent of 720 chill units). The fifth set of cuttings was left untreated to serve as a control.

For the monitoring of growth, each condition was replicated four times, and each replicate consisted of 20 -single-node cuttings. After the treatments, the basal ends of the shoots were cut under water to prevent air bubbles from forming inside the xylem vessels which would inhibit water uptake ${ }^{35}$. The cuttings were then placed in trays containing distilled water such that $\sim 1 \mathrm{~cm}$ of their base remained immersed. The trays were placed in a growth chamber set to $22^{\circ} \mathrm{C}, 14 \mathrm{H}$ light- and $18^{\circ} \mathrm{C}, 10 \mathrm{H}$ dark-period to force the buds to grow. Relative humidity was maintained at $95 \%$ and fluorescence light having a flux density of $150 \mu \mathrm{mol} \mathrm{m}^{-2} \mathrm{~s}^{-1}$ was used. The phenological stage of each bud was assessed every two days for 16 days. The buds were assigned with standard growth stages, i.e. dormant, swollen, green tip (when green tissue becomes visible) and open (when at least one fully expanded leaf becomes visible).

At the end of the forcing period, the largest leaf from each cutting (which grew) was harvested and its area was determined with a leaf Area Meter (LI-3100C). The average area per leaf was then calculated for each replicate. The percentage of cuttings which rooted was also determined for each treatment.

To obtain bud tissue for biochemical analyses, each of the treatments control, 5-min plasma and chilling were applied to extra three sets of 30-cutting each as descried previously. These cuttings were then forced under the same conditions as the previous ones. Samples of buds were taken from these cuttings at 2, 8 and 14 days after treatment (DAT). These samples were immediately frozen in liquid nitrogen then stored at $-50{ }^{\circ} \mathrm{C}$ for future biochemical analyses.

Plasma generation apparatus and treatment conditions. The schematic of the planar Dielectric Barrier Discharge (DBD) used in this work is included as supplementary material (Supplementary Figure S1). The planar DBD consists of a $10 \mathrm{~cm}$ internal diameter, $1 \mathrm{~cm}$ height quartz ring with two pipe connectors on the side for the gas inlet and outlet. The top and bottom are covered by 1-mm thick glass plates. The two electrodes are present outside above and below the glass plates. The top glass plate can be removed to insert the samples to be treated. Two mass flow controllers were used to provide a constant flow of 2 litres / min of Helium gas ( $99.99 \%$ purity) with $0.5 \%$ admixture of oxygen which enter the chamber from one side through a tube and exit from the other. For plasma treatment, the buds were placed inside an air-tight quartz chamber without any metal parts. 
They were treated for specified time duration, at a constant applied power of $30 \mathrm{~W}$. The plasma treatments lasted 2,5 or 10 minutes..

Biochemical analyses. Catalase activity. For the biochemical analyses, bud tissues were grinded in liquid nitrogen, then $100 \mathrm{mg}$ of powdered tissue was extracted with $1 \mathrm{~mL}$ of cold potassium phosphate buffer $(50 \mathrm{mM}, \mathrm{pH} 7.5)$ containing $2 \%(\mathrm{w} / \mathrm{v})$ PVP and EDTA $(1 \mathrm{mM})^{15}$. After centrifugation at $4{ }^{\circ} \mathrm{C}$, the supernatants were directly used for measuring protein content and assaying enzyme activity. The activity of CAT was measured spectrophotometrically using the change in absorbance at $240 \mathrm{~nm}$ of a solution containing $\mathrm{H}_{2} \mathrm{O}_{2}$ using an extinction coefficient of $39.3 \mathrm{mM}^{-1} \mathrm{~cm}^{-1}$. The change in absorbance at per minute and milligram of protein gives us specific activity of the enzyme. Total soluble protein concentration is determined according to Bradford ${ }^{36}$, using BSA as a standard.

Proline content. Proline concentration in the bud extract was determined by the ninhydrin method as described by Bates et al. ${ }^{37}$. In short, $200 \mathrm{mg}$ of powdered dry bud tissue was extracted for $30 \mathrm{~min}$ with $5 \mathrm{~mL}$ of boiling methanol $(40 \%, v / v)$. Two millilitres of glacial acetic acid and $1 \mathrm{~mL}$ of the ninhydrin solution (consisting of $25 \%$ distilled water, $60 \%$ glacial acetic acid and $15 \%$ orthophosphoric acid) were added to $1 \mathrm{~mL}$ of the methanolic extract. The mixture was boiled for $30 \mathrm{~min}$, and toluene $(3 \mathrm{ml})$ was added after cooling the mixture on ice. The upper phase was separated then dehydrated with $\mathrm{NaSO}_{4}$. After incubation of the solution in the dark for at least two hours, the absorbance was read at $528 \mathrm{~nm}$.

Malondialdehyde concentration. Malondialdehyde levels were determined using the method described by ${ }^{38}$, which corrects for the interference of impurities in the thiobarbituric acid (TBA) reactive substances assay. Briefly, buds were repeatedly extracted with $80: 20(\mathrm{v} / \mathrm{v})$ ethanol/water containing $1 \mathrm{mg} \mathrm{mL}^{-1}$ butylated hydroxytoluene (BHT) using ultra-sonication. This was followed by centrifugation; then the supernatants were pooled and an aliquot of sample was combined with a volume of either (1) - TBA solution containing $20 \%(\mathrm{w} / \mathrm{v})$ trichloroacetic acid and $0.01 \%(\mathrm{w} / \mathrm{v})$ BHT, or $(2)+\mathrm{TBA}$ solution containing the above plus $0.65 \%(\mathrm{w} / \mathrm{v}) \mathrm{TBA}$. Those samples were incubated in test tubes at $95^{\circ} \mathrm{C}$ for $25 \mathrm{~min}$ and, after cooling, absorbance was read at 440,532, and $600 \mathrm{~nm}$. The following formula was used to calculate MDA equivalents $\left(\mathrm{nmol} \mathrm{mL}^{-1}\right)$ :

$$
106 \times((\mathrm{A}-\mathrm{B}) / 157,000),
$$

where $\mathrm{A}=(($ Abs $532+\mathrm{TBA})-($ Abs $600+\mathrm{TBA})-($ Abs $532-\mathrm{TBA}-\mathrm{Abs} 600-\mathrm{TBA}))$, and $\mathrm{B}=((\mathrm{Abs}$ $440+$ TBA - Abs $600+$ TBA $) \times 0.0571)$.

Hydrogen peroxide $\left(\mathrm{H}_{2} \mathrm{O}_{2}\right)$ content. The concentration of $\mathrm{H}_{2} \mathrm{O}_{2}$ (nmol g ${ }^{-1}$ fresh weight) in bud tissue was determined as described by ${ }^{39}$. In short, bud samples (about $300 \mathrm{mg}$ ) were ground into a fine powder in liquid nitrogen then homogenized in $3 \mathrm{ml}$ of $1 \%(\mathrm{w} / \mathrm{v})$ trichloroacetic acid (TCA). The extracts were centrifuged at $10,000 \times \mathrm{g}$ $\left(4^{\circ} \mathrm{C}\right)$ for $10 \mathrm{~min}$. The supernatant was collected, filtered and $0.75 \mathrm{ml}$ of the supernatants was added to $0.75 \mathrm{ml}$ of $10 \mathrm{mM}$ Potassium phosphate buffer ( $\mathrm{pH} 7.0$ ) and $1.5 \mathrm{ml}$ of $1 \mathrm{M}$ potassium iodide (KI). $\mathrm{H}_{2} \mathrm{O}_{2}$ content was determined at $390 \mathrm{~nm}$ using a standard calibration curve.

Statistical analyses. The data were subjected to analysis of variance (ANOVA) using OriginPro 2018 software. A Completely Randomized Design with four replicates of 20 cuttings each was used for growth analysis. Where applicable, the means were separated by Tukey test with a level of significance $P=0.05$. A similar analysis procedure was used for biochemical analyses results but only three replicates of 30 cuttings each were used.

\section{Results}

The pictures of untreated control, chilled, plasma-treated shoots of the grape variety Muscat of Alexandria, after ten days of forcing are shown in Fig. 1. In comparison to the untreated control buds (a), both the chilled (b) and 5-mn plasma-treated shoots (d) had an earlier budbreak and a higher percentage of open buds (as shown quantitatively in Fig. 2). The 2-min (c) and 10-min (e) treatments did also have slightly earlier bud development in comparison to control; however, the final percentage of open buds after 16 days of forcing was comparable at $39-44 \%$. The $50 \%$ budbreak mark was reached on the $9^{\text {th }}$ day of forcing by chilled and 5 minutes plasma-treated cuttings, that's a 9-day advance in budbreak compared to control shoots.

The distribution of buds among four early phenological stages every two days during forcing is depicted as stacked bar histograms in Fig. 2. The picture of specimens of buds at each of the four phenological stages of dormant, swollen, green-tip and budburst is shown above the histogram and marked with their representative colour as in the bar chart. The dormant (brown) refers to the state when the bud has no sign of growth. The swollen state (grey) refers to the slight increase in the size of the bud and opening of the scales. The green tip (yellow) signifies the stage when some green tissue was visible, but the leaves did not unfold yet. Budburst is the final stage when at least one leaf has fully emerged from the bud.

The control group in Fig. (2) indicates buds which were forced without any prior treatment. These buds did not show any sign of activity during the first seven days of forcing and the first signs of swelling appeared after nine days. After 16 days, about $50 \%$ of the buds reached green tip and about $40 \%$ reached budburst stages. The buds chilled in $4{ }^{\circ} \mathrm{C}$ cold for one month started to swell just after four days of forcing, much earlier than the untreated control buds. After 14 days of forcing, about $75 \%$ of the buds were open. The growth pattern of the cuttings which were exposed to plasma for 5 minutes was similar to that of the chilled cuttings.

The percentage of buds which reached budburst stage as a function of days of forcing is shown in Fig. 3. In comparison to untreated shoot cuttings, much higher percentages of open buds were achieved by the 5-minutes plasma and 1-month chilling treatments ( $74 \%$ and $76 \%$, respectively). The final percentage of budbreak was 


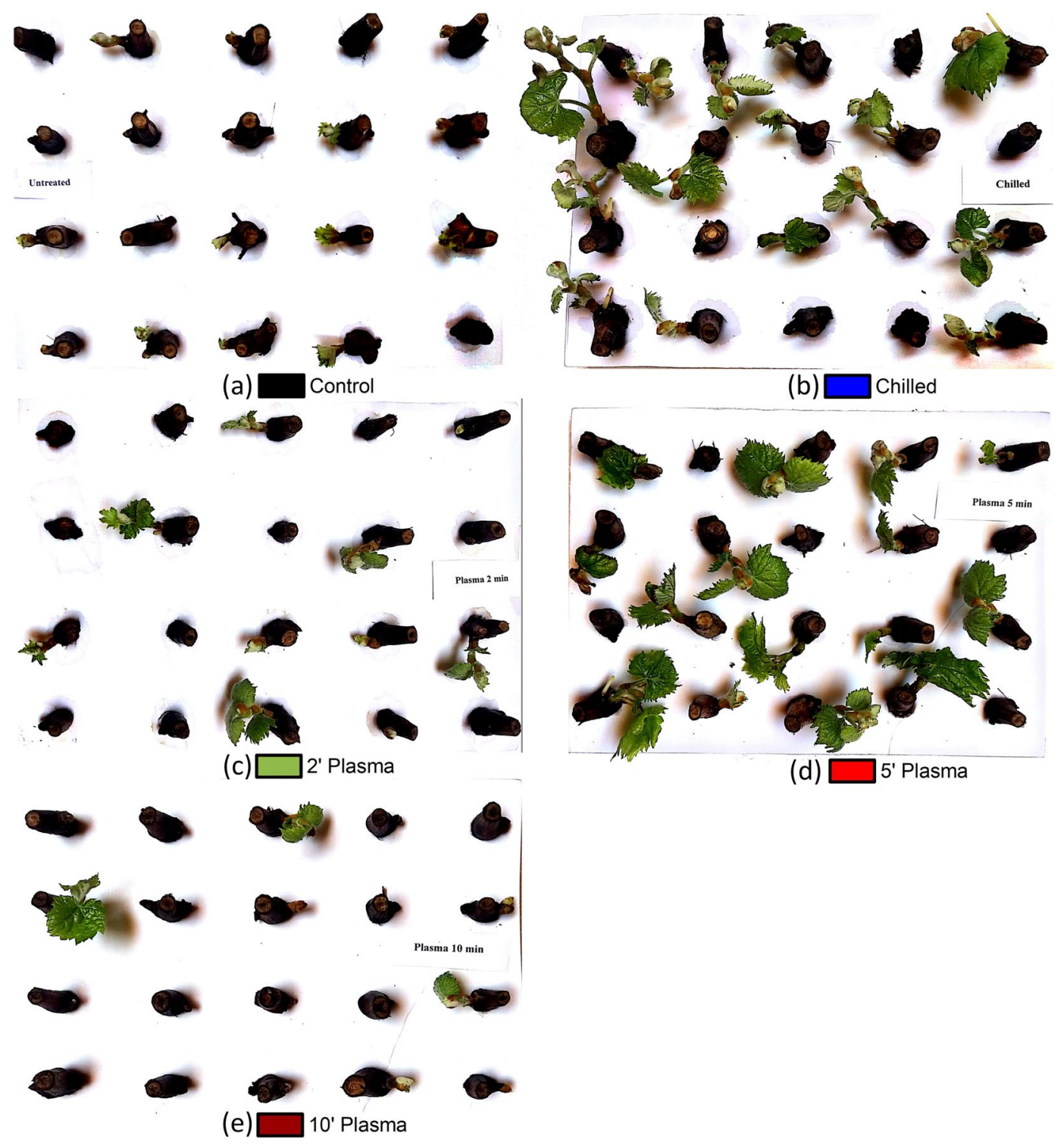

Figure 1. Growth of buds on single-node cuttings of Muscat of Alexandria grape after 10 days of forcing under $22^{\circ} \mathrm{C}, 14 \mathrm{H}$ light- and $18^{\circ} \mathrm{C}, 10 \mathrm{H}$ dark-period conditions. Prior to forcing, the cuttings were either untreated (control) (a), chilled for 1 -month at $4^{\circ} \mathrm{C}(\mathbf{b})$ or treated with cold atmospheric plasma for 2 (c), 5 (d) or 10 (e) min. Each picture represents one out of the four replicates of each treatment.

$39 \%$ on untreated cuttings. The 2 - and 10 -min plasma-treated buds started opening slightly earlier than the control; however, the final percentage after 16 days of forcing was comparable to the control at $\sim 44 \%$.

Close examination of cross-sections of several plasma-treated buds did not reveal any damage to the primary bud within the compound buds (Fig. 4b). However, we do see some darkening of some secondary buds and the peripheral tissues in the primary buds treated with plasma for $10 \mathrm{~min}$ possibly due to damage to these tissues. The vascular tissues underlying the bud do not show any signs of damage (Fig. 4c).

The comparison of the average area per leaf of new shoots from each treatment after 16 days of forcing is shown in Fig. 5 (Left). This is the area of the largest leaf on each cutting which grew and then the average area per leaf from each replicate was calculated. Plasma-treated cuttings had larger leaves then control and chilled cuttings $(P<0.01)$. The leaf area increased from $4.9 \mathrm{~cm}^{2}$ in control buds to $\sim 8.7,10.6$ and $8.3 \mathrm{~cm}^{2}$ after 2,5 and 10 minutes of plasma treatment, respectively. The $5 \mathrm{~min}$ treatment gave a larger leaf area than the chilled and control $(P<0.01)$, whereas the 10 and 2 min treatments tended to have larger leaf area than the control and chilled treatments $(P=0.14$ and 0.22 , respectively). Surprisingly, under these criteria the leaf area of chilled buds was slightly smaller than that of control buds $\left(4.1 \mathrm{~cm}^{2}\right)$. Exposure to plasma or cold appears to have a profound effect on rhizogenesis (Fig. 5 - Right). The percentage of stems which developed roots sharply increased in all four treatments compared to control $(P<0.01)$.

Figure 6 shows the change in the concentrations of free proline, MDA and $\mathrm{H}_{2} \mathrm{O}_{2}$ and CAT activity in bud tissues of Muscat of Alexandria grape shoot cuttings after 2, 8 and 14 days of forcing under warm long day 


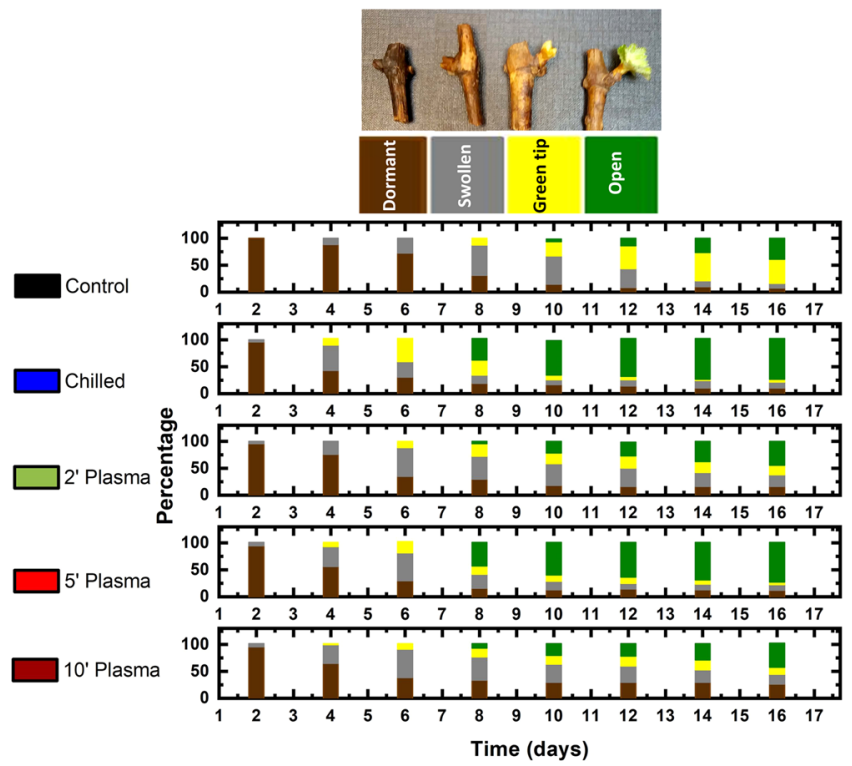

Figure 2. The percentage of buds at each phenological stage as a function of days of forcing under $22^{\circ} \mathrm{C}, 14 \mathrm{H}$ light- and $18^{\circ} \mathrm{C}, 10 \mathrm{H}$ dark-period conditions on Muscat of Alexandria grape shoot cuttings. Prior to forcing, the cuttings were either untreated (control), chilled for 1 -month at $4{ }^{\circ} \mathrm{C}$ or treated with cold atmospheric plasma for 2, 5 or $10 \mathrm{~min}$. Each bar represents the mean of four replicates of 20 cuttings each. A picture of specimens of buds representing each of the four phenological stages of dormant, swollen, green-tip and budburst is shown above the histogram.

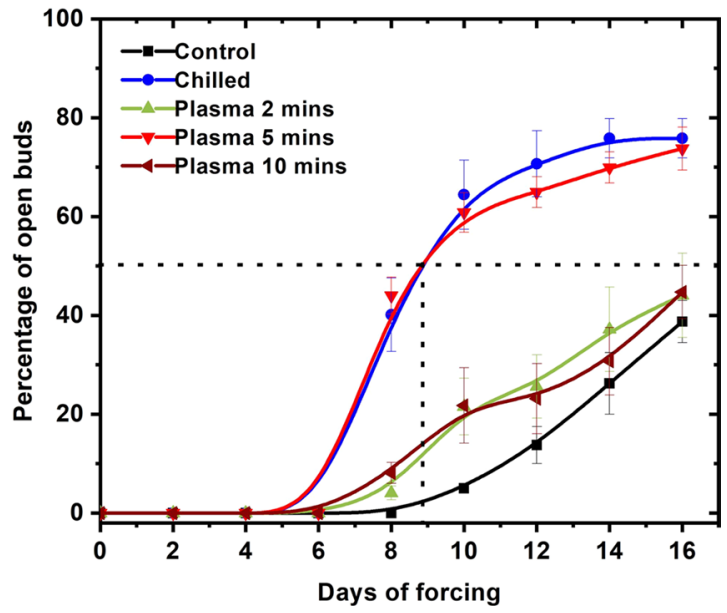

Figure 3. The percentage of buds which reached budburst stage as a function of days of forcing under $22^{\circ} \mathrm{C}, 14 \mathrm{H}$ light- and $18^{\circ} \mathrm{C}, 10 \mathrm{H}$ dark-period conditions on Muscat of Alexandria grape shoot cuttings. Prior to forcing, the cuttings were either untreated (control), chilled for 1 -month at $4{ }^{\circ} \mathrm{C}$ or treated with cold atmospheric plasma for 2, 5 or $10 \mathrm{~min}$. Each point represents the mean $\pm \mathrm{SE}$ of four replicates of 20 cuttings each.

conditions. After two days of forcing, 5-min plasma-treated samples had the highest concentration of proline $(P<0.01)$ (Fig. 6). Compared to the control samples which had $0.56 \mu \mathrm{mol} \mathrm{g}{ }^{-1} \mathrm{FW}$, the $5 \mathrm{~min}$ plasma-treated samples had a phenomenally high proline concentration of $7.85 \mu \mathrm{mol} \mathrm{g}^{-1} \mathrm{FW}$, i.e. almost fourteen times higher. The chilled buds had a concentration of $2.85 \mu \mathrm{mol} \mathrm{g}{ }^{-1} \mathrm{FW}$, which is much higher than the control but about a third of what was measured in plasma-treated buds. On day 8 of forcing, proline concentrations were significantly less than on day 2 for all three treatments. However, still, the $5 \mathrm{~min}$ plasma-treated buds had the highest concentration at $3.3 \mu \mathrm{mol} \mathrm{g}^{-1} \mathrm{FW}$. While the control and the chilled buds had 0.2 and $1.05 \mu \mathrm{mol} \mathrm{g}^{-1} \mathrm{FW}$, respectively. On day 14 , the concentration of proline in plasma-treated buds did not change significantly but it increased markedly in control and chilled buds.

After two days of forcing, the concentration of MDA was slightly higher in the tissues of untreated buds compared to cold- and plasma-treated buds (Fig. 6) $(P<0.01)$. Control buds had a MDA concentration of 37.7 

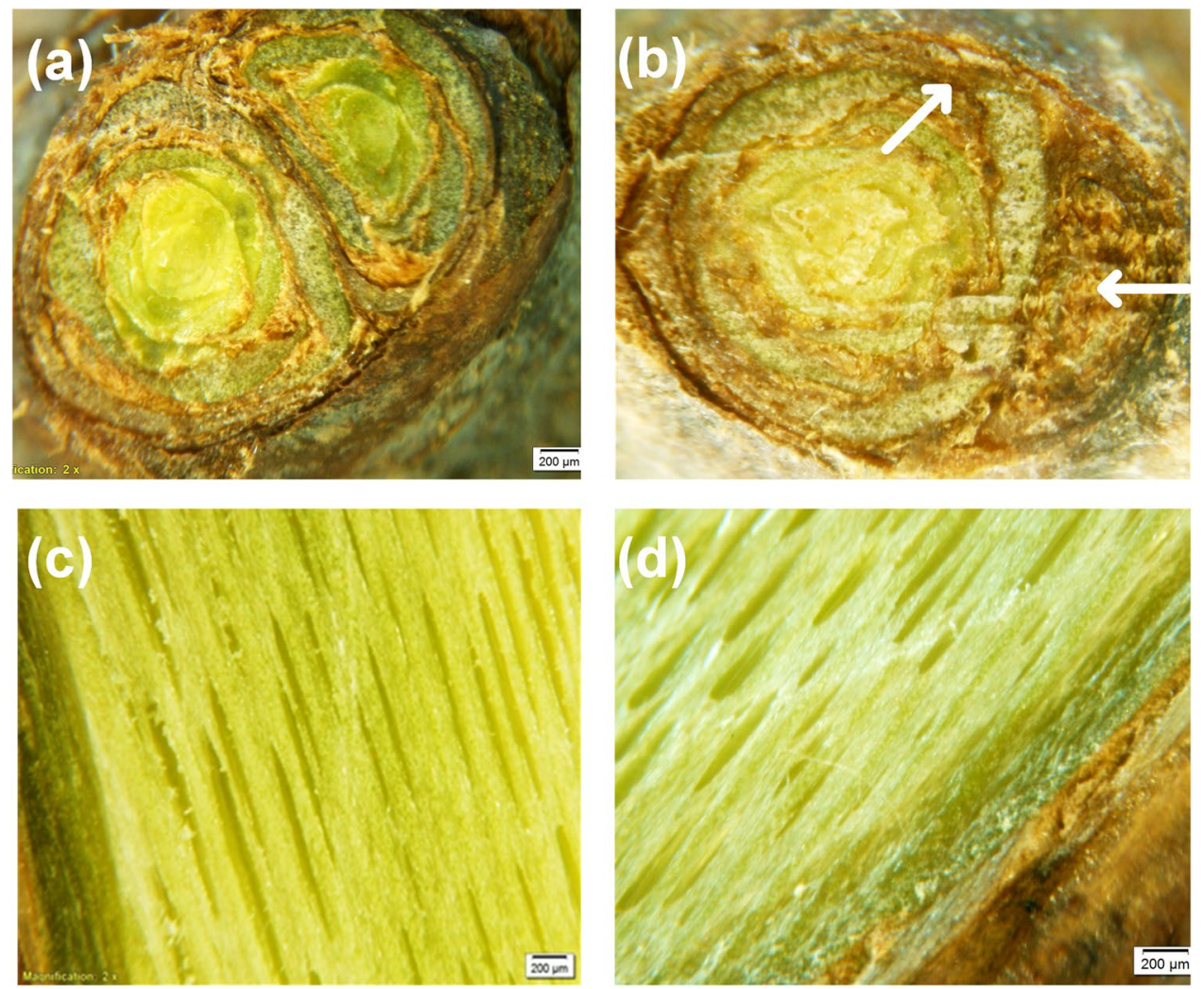

Figure 4. Above, cross-sections of dormant buds of Muscat of Alexandria grape after three days of forcing under $22^{\circ} \mathrm{C}, 14 \mathrm{H}$ light- and $18^{\circ} \mathrm{C}, 10 \mathrm{H}$ dark-period conditions. Prior to forcing, the cuttings were either untreated (control) (a) or treated with cold atmospheric plasma for $10 \mathrm{~min}$ (b). Below are photographs of vascular tissues from the stem below the bud of control (c) and plasma-treated cuttings (d). Arrows indicate brown tissue potentially damaged by exposure to plasma.

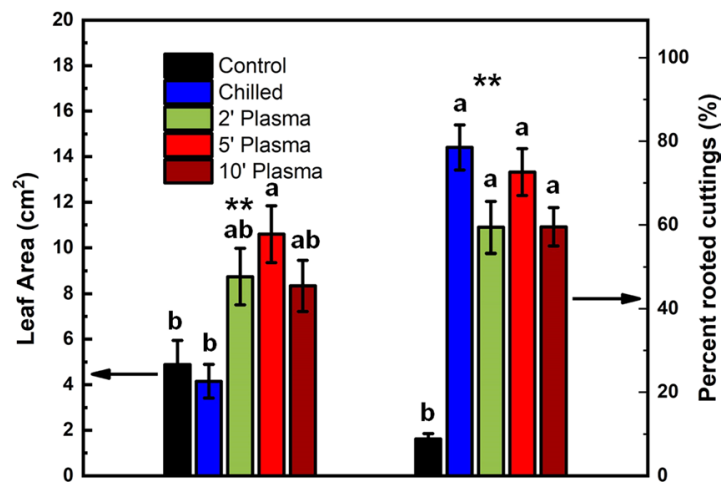

Figure 5. Average leaf area (left) and percentage of rooted cuttings (right) in untreated control, 2-, 5- and 10min plasma treated and 1-month chilled Muscat of Alexandria grape shoot cuttings after 16 days of forcing under $22^{\circ} \mathrm{C}, 14 \mathrm{H}$ light- and $18^{\circ} \mathrm{C}, 10 \mathrm{H}$ dark-period conditions. Each bar represents the mean $\pm \mathrm{SE}$ of four replicates of 20 cuttings each. For each tissue, the bars marked with different letters represent means which are significantly different at $P<0.05$. ${ }^{* *}$ The differences among the treatments are significant at $P<0.01$.

$\mathrm{nmol} \mathrm{g}^{-1} \mathrm{FW}$ of bud tissue. Six days later, the concentration increased in untreated and plasma-treated buds but not in chilled ones. MDA concentrations changed to 43.7, 25.7 and 57.1 for the control, chilled and 5 min plasma treatments, respectively.

The change with forcing time in CAT activity (unit $\mathrm{mg}^{-1}$ protein) in untreated, chilled and 5 min plasma treated cuttings is shown in Fig. 6. After two days of forcing, control buds had the lowest activity of CAT, with 15 -unit $\mathrm{mg}^{-1}$ protein $(P<0.05)$. The activity was higher in cold- and plasma-treated buds. After 8 days of forcing, CAT activity almost doubled in control and chilled buds but remained unchanged in plasma-treated buds. 

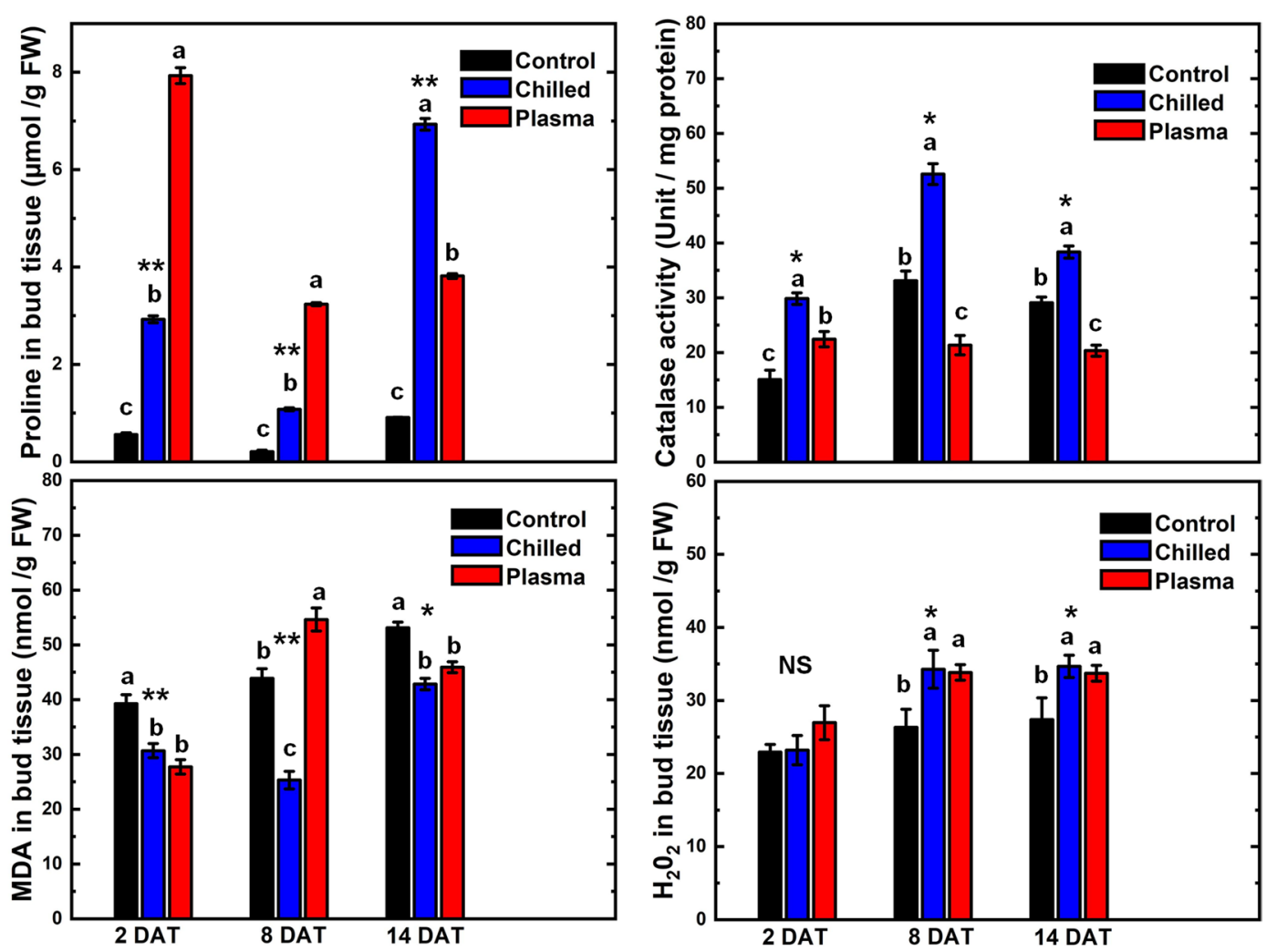

Figure 6. The concentrations of free proline, malondialdehyde (MDA) and hydrogen peroxide (H2O2) and catalase activity (CAT) in bud tissue of Muscat of Alexandria grape shoot cuttings after 2, 8 and 14 days of forcing under $22^{\circ} \mathrm{C}, 14 \mathrm{H}$ light- and $18^{\circ} \mathrm{C}, 10 \mathrm{H}$ dark-period conditions. Prior to forcing, the cuttings were either untreated (control), chilled for 1 -month at $4^{\circ} \mathrm{C}$ or treated with cold atmospheric plasma for $5 \mathrm{~min}$. Each bar represents the mean $\pm \mathrm{SE}$ of three determinations. For each date, the bars marked with different letters

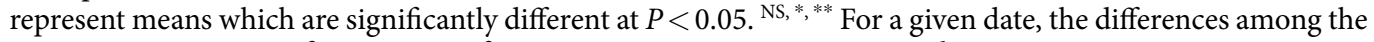
treatments are not significant, or significant at $P<0.05$ or $<0.01$, respectively.

Just like with proline, CAT activity increased after 8 days of forcing in chilled samples compared to control. The activity in the cuttings which received these two treatments decreased slightly on day 14 of forcing; whereas, in plasma-treated buds the level of CAT activity remained the same throughout the forcing period.

The change over time of $\mathrm{H}_{2} \mathrm{O}_{2}$ concentration in untreated, chilled and 5 min plasma treated shoot cuttings is shown in Fig. 6. After two days of forcing, plasma-treated buds tended to have a slightly higher concentration of $\mathrm{H}_{2} \mathrm{O}_{2}$ than those which received the other treatments $(P=0.12)$. On days 8 and 14 of forcing, chilled and plasma-treated buds had higher concentrations of $\mathrm{H}_{2} \mathrm{O}_{2}$ than untreated buds in which the concentration changed little over time $(P<0.05)$.

\section{Discussion}

The results show that the final percentage of budbreak on cuttings which were exposed to plasma for 5 minutes or to chilling temperature for one month increased by $\sim 100 \%$ over that of control cuttings. Also, cuttings treated with plasma for $5 \mathrm{~min}$ reached $50 \%$ budbreak 9 days ahead of untreated cuttings. The 2 and 10 min plasma-treated buds started opening slightly earlier than the control; however, the final percentage of budbreak was comparable to that of untreated cuttings. This indicates that the $2 \mathrm{~min}$ was probably not enough to stimulate budbreak, whereas the $10 \mathrm{~min}$ may have started damaging the outside layer of the buds. In fact, a close examination of cross-sections of several plasma-treated buds for $10 \mathrm{~min}$ did not reveal any damage to the primary buds within the compound buds; however, some secondary buds and the peripheral tissues in some primary buds turned brownish indicating possible damage to these tissues. Furthermore, a small percentage of the buds may have been fatally injured as suggested by the fact that about $25 \%$ of the buds appeared dormant after 16 days of forcing compared to less than $5 \%$ on untreated cuttings. The vascular tissues underlying the bud did not show any signs of damage. Therefore, the reduction in budbreak on cuttings exposed to plasma for 10 minutes may have been caused by an inactivation of some of their primary buds rather than an outright killing of the meristems. There is no previous work with plasma on buds to compare with, but experiments on seeds show that there is an optimum duration of exposure to plasma beyond which germination decreases ${ }^{22}$.

The comparison of sprouting vigour, as inferred from the size of the new leaves, indicates that exposure to plasma had a stimulating effect on shoot growth. The average area per leaf for each treatment was largest for the plasma-treated cuttings and especially the 5-minute treatment. In addition to releasing the dormancy of 
meristems and predisposing them for fast growth resumption, plasma may have also suppressed fungal growth thus allowing leaves to become larger. It is known that non-thermal plasma treatment reduces the fungal growth and up-regulates resistance genes in plants ${ }^{40,41}$.

A surprising finding was the positive effect of plasma on rhizogenesis. The final percentage of cuttings which developed roots was more than $70 \%$ for cold and 5 minutes plasma treatments compared to $\sim 60 \%$ for the 2 - and 10 -minutes plasma and less than $10 \%$ for the control. This shows that even a short exposure to plasma affects the shoots in a way similar to chilling. Plasma treatment encouraged both budbreak and root differentiation as efficiently as cold temperature. The percentage is much higher in all treated samples compared to the control samples. This indicates that the plasma treatment altered the hormonal balance of the cuttings in favour of sprouting and rhizogenesis. Similarly, when tobacco seedlings were subjected to drought stress, they accumulate auxin and develop more lateral roots ${ }^{42}$.

So far, a direct relationship between the ROS signaling and changes in membranes functioning and structure has not been reported for dormant buds. However, it has been shown that the hydroxyl radical OH plays a direct role in processes leading to membrane loosening in germinating seeds ${ }^{43}$. It is therefore possible that ROS signaling could be involved in cell wall loosening leading to the release of bud dormancy. Numerous studies were carried out to unravel the mechanisms underlying the process of dormancy release in buds of temperate zone tree and vine species. Most of these studies agree that stresses, especially oxidative and respiratory stresses, play a role in the release of bud dormancy ${ }^{13,15,44,45}$. Due to these stresses, ROS are produced which affects the growth and development of plant in various ways ${ }^{44}$. For instance, exogenous application of $\mathrm{H}_{2} \mathrm{O}_{2}$ can substitute for chilling by initiating a series of events which eventually lead to the release of bud dormancy ${ }^{46}$. Still ROS in high levels have harmful effects and must be strictly controlled to fulfill their role as cellular messengers ${ }^{44}$. Hence, the antioxidant control systems involving the enzymes CAT, superoxide dismutase (SOD) and peroxidase (POD) are upregulated during dormancy release to check the level of ROS in plant tissues. In grape buds, the interconnections between bud dormancy status, CAT activity and $\mathrm{H}_{2} \mathrm{O}_{2}$ concentration levels were well demonstrated. It was found that the application of CAT inhibitors or exogenous $\mathrm{H}_{2} \mathrm{O}_{2}$ induce dormancy breakage by favoring the oxidative pentose phosphate pathway (PPP) which presumably provides reducing power and carbon for the new growth ${ }^{47}$.

In the present study, the concentration of $\mathrm{H}_{2} \mathrm{O}_{2}$ in cold-treated buds early in the forcing period was comparable to its level in control buds possibly due to the higher CAT activity; therefore, membrane lipid peroxidation, as indicated by MDA concentration, was lower than what was detected in control buds. As budbreak proceeded and growth accelerated, one would presume that nitrogen and sugar reserves were mobilized and respiration intensified with potentially more production of $\mathrm{H}_{2} \mathrm{O}_{2}$. In response, CAT activity increased but apparently not enough to prevent an increase in lipid peroxidation (Fig. 6).

CAT activity was slightly higher in plasma-treated tissues compared to control buds but remained unchanged throughout the forcing period as opposed to the activity in control and chilled buds which increased markedly compared to the start of forcing. Understandably, the level of $\mathrm{H}_{2} \mathrm{O}_{2}$ increased too as forcing proceeded leading to some membrane damage as indicated by the higher concentration of MDA and the browning of peripheral tissues in some buds. Our results show that CAT activity, the main $\mathrm{H}_{2} \mathrm{O}_{2}$ degrading enzyme, increased gradually in the chill-treated buds of grapevine during dormancy breakage, and this response was parallel to a slight increase in the level of $\mathrm{H}_{2} \mathrm{O}_{2}$ and a decrease in the level of MDA after 8 days of forcing (Fig. 6). This indicates that the strong activity of CAT in the chill-treated buds either at the beginning of the forcing period or after 8 days effectively guarded against peroxidation of cell membrane lipids. Nevertheless, the slight increase of $\mathrm{H}_{2} \mathrm{O}_{2}$ in chilled bud tissues may have generated a moderate oxidative stress or may have acted as a chemical signal that triggered the expression of genes related to endodormancy release $\mathrm{e}^{48,49}$. In addition, chilling treatment led to a quick accumulation of free proline in the bud tissues (Fig. 6). This common stress response was previously reported in response to treatment with cold ${ }^{50}$ or hydrogen cyanimide ${ }^{16,51}$. Still the highest increase in proline content was caused by the 5-min plasma treatment $(P<0.01)$, which peaked after 2 days of forcing then decreased possible due to turnover and for being used as a source of nitrogen and carbon by the developing bud structures. The high level of proline was matched by a low CAT activity. Proline was shown to increase the activity of POD and decrease the activities of CAT and SOD in grapevine tissue ${ }^{52}$. A similar result was reported when grape buds were sprayed with hydrogen cyanimide ${ }^{14-16}$. Accordingly, compared to chilling, it appears that the plasma treatment triggered a more intense but transient oxidative stress as indicated by the temporary increase of MDA content especially on the $8^{\text {th }}$ day of forcing. Such oxidative stress is part of the mechanism leading to budbreak in both treatments. Furthermore, the sharp increase in proline biosynthesis in the case of plasma treatment may have led to an increase in $\mathrm{NADP}^{+} / \mathrm{NADPH}$ ratio and then the activation of the oxidative pentose phosphate pathway which is important for antioxidative defense and dormancy breakage ${ }^{47,53}$. Proline can also stabilize sub-cellular structures, quench active oxygen and protect cells against the adverse effects of stress ${ }^{54}$. The response of grape buds to cold plasma appears similar to that of chilling and artificial rest-breaking chemicals ${ }^{48,55}$. Proline seems to play a key role in this response: when it accumulates, it protects the cells against oxidative stress and upregulates the oxidative pentose phosphate pathway causing a series of events which lead to the release of dormancy. When the stress abates, proline is degraded giving way to new metabolite compounds used by anabolic pathways which yield the ATP, phosphorylated sugars and amino-acids needed to initiate budbreak and active growth resumption ${ }^{51}$.

\section{Conclusion}

In this work, we report on a novel plasma-based environmentally friendly treatment of dormant grape buds. The plasma-based treatment has shown a large improvement of several growth parameters including an earlier and more synchronous bud growth and a higher final percentage of budbreak compared to untreated buds. Cuttings exposed to plasma for 5 minutes also had larger leaves and developed more roots.

Several previous studies suggested that the release of buds dormancy involves stresses, especially oxidative stresses. In grape buds, the interconnection between dormancy release and oxidative processes is well established. 
When the buds were exposed to plasma, their tissues accumulated the amino-acid proline and $\mathrm{H}_{2} \mathrm{O}_{2}$ whereas CAT activity remained stable; this appears to have led to an intense but transient oxidative stress which induced the meristems to resume active growth and the buds to open earlier and in larger numbers. It appears that $\mathrm{H}_{2} \mathrm{O}_{2}$ and proline are key factors in the process; the former directly or indirectly caused the oxidative stress while the latter helped protect cell membranes against free radicals and possibly upregulated the oxidative pentose phosphate pathway prompting a chain of events leading to dormancy release.

We anticipate that our work will provide a starting point for the development of novel plasma-based tools and methods to treat dormant plants whether ex-situ or in the field. This technique will be an effective and safer alternative to chemical dormancy-breaking substances. Furthermore, the plasma treatment method may allow higher agricultural production in several regions of the world, at risk of becoming marginal due to global warming ${ }^{7}$.

\section{Data availability}

The datasets generated during and/or analysed during the current study are available from the corresponding author on reasonable request.

Received: 11 March 2019; Accepted: 23 January 2020;

Published online: 14 February 2020

\section{References}

1. Lang, G. Endo-, para-, and ecodormancy: physiological terminology and classification for dormancy research. HortScience 22, 371-377 (1987)

2. Westwood, M. Plant efficiency: growth and yield measurements. Temperate Zone Pomology (3rd ed.). Timber Press, Portland, OR, USA, 220-228 (1993).

3. Faust, M. Bud dormancy in perennial fruit trees: physiological basis for dormancy induction, maintenance, and release. HortScience 32, 623-629 (1997).

4. Nir, G. \& Lavee, S. Metabolic changes during cyanamide induced dormancy release in grapevines. Acta Hortic. 329, 271-274 (1993).

5. Erez, A. Means to compensate for insufficient chilling to improve bloom and leafing actahortic. Acta Hortic. 395, 81-96 (1995).

6. Mohamed, H. B., Vadel, A. M., Geuns, J. M. \& Khemira, H. Biochemical changes in dormant grapevine shoot tissues in response to chilling: possible role in dormancy release. Sci. Hortic. 124, 440-447 (2010).

7. Luedeling, E. Climate change impacts on winter chill for temperate fruit and nut production: a review. Sci. Hortic. 144, 218-229 (2012).

8. Trejo-Martínez, M. A., Orozco, J. A., Almaguer-Vargas, G., Carvajal-Millán, E. \& Gardea, A. A. Metabolic activity of low chilling grapevine buds forced to break. Thermochim. Acta 481, 28-31 (2009).

9. Mohamed, H. B., Vadel, A. M. \& Khemira, H. Estimation of chilling requirement and effect of hydrogen cyanamide on budbreak and fruit characteristics of 'Superior Seedless' table grape cultivated in a mild winter climate. Pak. J. Bot. 42, 1761-1770 (2010).

10. Mohamed, A. K. A. The effect of chilling, defoliation and hydrogen cyanamide on dormancy release, bud break and fruiting of Anna apple cultivar. Sci. Hortic. 118, 25-32 (2008).

11. Powell, A. A., Himelrick, D. G. \& Tunnell, E. Effect of hydrogen cyanamide (dormext) on replacing lack of chilling in kiwifruit (Actinidia deliciosa). Small Fruits Rev. 1, 79-92 (2000).

12. Fuchigami, L. H. Degree growth stage model and rest-breaking mechanism in temperate woody perennials. HortScience 22, 836-845 (1987).

13. Or, E., Vilozny, I., Fennell, A., Eyal, Y. \& Ogrodovitch, A. Dormancy in grape buds: isolation and characterization of catalase cDNA and analysis of its expression following chemical induction of bud dormancy release. Plant Sci. 162, 121-130 (2002).

14. Pérez, F. J. \& Lira, W. Possible role of catalase in post-dormancy bud break in grapevines. J. Plant Physiol. 162, 301-308 (2005).

15. Ben Mohamed, H., Vadel, A. M., Geuns, J. M. C. \& Khemira, H. Effects of hydrogen cyanamide on antioxidant enzymes' activity, proline and polyamine contents during bud dormancy release in Superior Seedless grapevine buds. Acta Physiol. Plant. 34, 429-437 (2012).

16. Halaly, T. et al. Similar mechanisms might be triggered by alternative external stimuli that induce dormancy release in grape buds. Planta 228, 79-88 (2008).

17. Pacey-Miller, T. et al. Genes associated with the end of dormancy in grapes. Func. Integ. Genom. 3, 144-152 (2003).

18. Ben Mohamed, H., Vadel, A. M., Geuns, J. M. C. \& Khemira, H. Carbohydrate changes during dormancy release in Superior Seedless grapevine cuttings following hydrogen cyanamide treatment. Sci. Hortic. 140, 19-25 (2012).

19. Puac, N., Gherardi, M. \& Shiratani, M. Plasma agriculture: A rapidly emerging field. Plasma Process. Polym. 15, 00174 (2017).

20. Ito, M., Ohta, T. \& Hori, M. Plasma Agriculture. J. Korean Phys. Soc. 60, 937-943 (2012).

21. Graves, D. B. Low temperature plasma biomedicine: A tutorial review. Phys. Plasmas 21, 080901 (2014).

22. Matra, K. Atmospheric non-thermal argon-oxygen plasma for sunflower seedling growth improvement. Jpn. J. Appl. Phys. 57, 01AG03 (2018).

23. Gómez-Ramírez, A. et al. Surface chemistry and germination improvement of Quinoa seeds subjected to plasma activation. Sci. Rep. 7, 5924 (2017).

24. Meng, Y. R. et al. Enhancement of Germination and Seedling Growth of Wheat Seed Using Dielectric Barrier Discharge Plasma with Various Gas Sources. Plasma Chem. Plasma P. 37, 1105-1119 (2017).

25. Zhang, J. J. et al. Growth-inducing effects of argon plasma on soybean sprouts via the regulation of demethylation levels of energy metabolism-related genes. Sci. Rep. 7, 41917 (2017).

26. Zhou, R. W. et al. Effects of Atmospheric-Pressure N-2, He, Air, and O-2 Microplasmas on Mung Bean Seed Germination and Seedling. Growth. Sci. Rep. 6, 32603 (2016).

27. Liao, X. Y. et al. Inactivation mechanisms of non-thermal plasma on microbes: A review. Food Control 75, 83-91 (2017).

28. Li, Y. J. et al. Air Atmospheric Dielectric Barrier Discharge Plasma Induced Germination and Growth Enhancement of Wheat Seed. Plasma Chem. Plasma P. 37, 1621-1634 (2017).

29. Dubinov, A. E., Kozhayeva, J. P. \& Zuimatch, E. A. Changing Germination Rate of Brown Mustard Seeds After Treatment With Plasmas of Nanosecond Electric Discharges. IEEE T. Plasma Sci. 45, 294-300 (2017).

30. Velichko, I., Pazderu, K. \& Pulkrabek, J. Cold Plasma Seed Treatment and its Effect on Plant Growing. (2017).

31. Li, L., Li, J. G., Shen, M. C., Zhang, C. L. \& Dong, Y. H. Cold plasma treatment enhances oilseed rape seed germination under drought stress. Sci. Rep. 5, 13033 (2015).

32. Roy, N. C., Hasan, M. M., Talukder, M. R., Hossain, M. D. \& Chowdhury, A. N. Prospective Applications of Low Frequency Glow Discharge Plasmas on Enhanced Germination, Growth and Yield of Wheat. Plasma Chem. and Plasma P. 38, 13-28 (2018).

33. Meiqiang, Y., Mingjing, H., Buzhou, M. \& Tengcai, M. Stimulating effects of seed treatment by magnetized plasma on tomato growth and yield. Plasma Sci. Technol. 7, 3143 (2005). 
34. Dhayal, M., Lee, S.-Y. \& Park, S.-U. Using low-pressure plasma for Carthamus tinctorium L. seed surface modification. Vacuum 80 , 499-506 (2006).

35. Balandier, P., Bonhomme, M., Rageau, R., Capitan, F. \& Parisot, E. Leaf bud endodormancy release in peach trees: evaluation of temperature models in temperate and tropical climates. Agr. Forest Meteorol. 67, 95-113 (1993).

36. Bradford, M. M. A rapid and sensitive method for the quantitation of microgram quantities of protein utilizing the principle of protein-dye binding. Anal. Biochem. 72, 248-254 (1976).

37. Bates, L. S., Waldren, R. P. \& Teare, I. Rapid determination of free proline for water-stress studies. Plant Soil 39, 205-207 (1973).

38. Hodges, D. M., DeLong, J. M., Forney, C. F. \& Prange, R. K. Improving the thiobarbituric acid-reactive-substances assay for estimating lipid peroxidation in plant tissues containing anthocyanin and other interfering compounds. Planta 207, 604-611 (1999).

39. Loreto, F. \& Velikova, V. Isoprene produced by leaves protects the photosynthetic apparatus against ozone damage, quenches ozone products, and reduces lipid peroxidation of cellular membranes. Plant Physiol. 127, 1781-1787 (2001).

40. Panngom, K. et al. Non-thermal plasma treatment diminishes fungal viability and up-regulates resistance genes in a plant host. Plos One 9 , e99300 (2014).

41. Siddique, S., Hardy, G. S. J. \& Bayliss, K. Cold plasma: a potential new method to manage postharvest diseases caused by fungal plant pathogens. Plant Pathol. 67, 1011-1021 (2018).

42. Wang, C. et al. Auxin is Involved in Lateral Root Formation Induced by Drought Stress in Tobacco Seedlings. J. Plant Growth Regul. 37, 539-549 (2018).

43. Müller, K. et al. In vivo cell wall loosening by hydroxyl radicals during cress seed germination and elongation growth. Plant Physiol. 150, 1855-1865 (2009).

44. Considine, M. J. \& Foyer, C. H. Redox regulation of plant development. Antioxid. Redox Sign. 21, 1305-1326 (2014).

45. Carvalho, L. C., Vidigal, P. \& Amâncio, S. J. Oxidative stress homeostasis in grapevine (Vitis vinifera L.). Front. Environ. Sci. 3, 20 (2015).

46. Perez, F. J., Vergara, R. \& Rubio, S. $\mathrm{H}(2) \mathrm{O}(2)$ is involved in the dormancy-breaking effect of hydrogen cyanamide in grapevine buds. Plant Growth Regul. 55, 149-155 (2008).

47. Tian, W.-N. et al. Importance of glucose-6-phosphate dehydrogenase activity for cell growth. J. Biol. Chem. 273, 10609-10617 (1998).

48. Perez, F. J., Vergara, R. \& Or, E. On the mechanism of dormancy release in grapevine buds: a comparative study between hydrogen cyanamide and sodium azide. Plant Growth Regul. 59, 145-152 (2009).

49. Tan, Y. et al. Relationships between $\mathrm{H} 2 \mathrm{O} 2$ metabolism and $\mathrm{Ca} 2+$ transport in dormancy-breaking process of nectarine floral buds. J. Appl. Ecol. 26, 425-429 (2015).

50. Ben Mohamed, H., Vadel, A. M., Geuns, J. M. C. \& Khemira, H. Biochemical changes in dormant grapevine shoot tissues in response to chilling: Possible role in dormancy release. Sci. Hortic. 124, 440-447 (2010).

51. Walton, E. F., Podivinsky, E., Wu, P. M., Reynolds, P. H. S. \& Young, L. W. Regulation of proline biosynthesis in kiwifruit buds with and without hydrogen cyanamide treatment. Physiol. Plant. 102, 171-178 (1998).

52. Ozden, M., Demirel, U. \& Kahraman, A. J. Effects of proline on antioxidant system in leaves of grapevine (Vitis vinifera L.) exposed to oxidative stress by $\mathrm{H}_{2} \mathrm{O}_{2}$. Sci. Hortic. 119, 163-168 (2009).

53. Hare, P. \& Cress, W. J. Metabolic implications of stress-induced proline accumulation in plants. Plant Growth Regul. 21, 79-102 (1997).

54. Ashraf, M. \& Foolad, M. Roles of glycine betaine and proline in improving plant abiotic stress resistance. Environ. Exp. Bot. 59, 206-216 (2007).

55. Walton, E. F. et al. A rapid transcriptional activation is induced by the dormancy-breaking chemical hydrogen cyanamide in kiwifruit (Actinidia deliciosa) buds. J. Exp. Bot. 60, 3835-3848 (2009).

\section{Acknowledgements}

The authors would like to acknowledge King Abdul Aziz City for Science and Technology (KACST) GDRG Project Number 37-146.

\section{Author contributions}

Z.M. and H.K. conceived the idea and designed the experiments. Z.M. built the plasma system and performed the plasma treatment. H.K. sourced and prepared shoot cuttings, monitored bud growth and measured leaf area and rooting percentages. H.K. and Z.M. analyzed the growth data. T.T. and H.K. performed the biochemical analyses. Z.M. and H.K. wrote the paper and T.T. and H.K. discussed the physiological significance of the data. All authors contributed to the editing of the manuscript.

\section{Competing interests}

The authors declare no competing interests.

\section{Additional information}

Supplementary information is available for this paper at https://doi.org/10.1038/s41598-020-59097-x.

Correspondence and requests for materials should be addressed to H.K.

Reprints and permissions information is available at www.nature.com/reprints.

Publisher's note Springer Nature remains neutral with regard to jurisdictional claims in published maps and institutional affiliations.

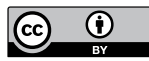

Open Access This article is licensed under a Creative Commons Attribution 4.0 International License, which permits use, sharing, adaptation, distribution and reproduction in any medium or format, as long as you give appropriate credit to the original author(s) and the source, provide a link to the Creative Commons license, and indicate if changes were made. The images or other third party material in this article are included in the article's Creative Commons license, unless indicated otherwise in a credit line to the material. If material is not included in the article's Creative Commons license and your intended use is not permitted by statutory regulation or exceeds the permitted use, you will need to obtain permission directly from the copyright holder. To view a copy of this license, visit http://creativecommons.org/licenses/by/4.0/.

(C) The Author(s) 2020 